3. Advanced traumatology

4. International politics and medical ethics

5. Tropical medicine and epidemic diseases

6. Disaster management

Based on this Danish Diploma Course and further work in COMEDS Working Group on Medical Training (WG-MT), COMEDS Plenary has agreed on a proposal for a NATOSTANAG to establish "Training Requirements for International Health Support" in its member countries. The Working Group on Medical Training is completing this new task of preparing a STANAG proposal for Military Acute Trauma Care Training.

Keywords: Danish Armed Foreces; civilians; COMEDS; epidemics; ethics; Gulf War; health services; management; peacesupporting; politics; STANAG; training; traumatology; tropical medicine

Prebosp Disast Med 2002;17:s7.

\section{Health Exams Caused by the Suspicion of a Connection between Depleted Uranium and Leukemia \\ Darre $E$}

Danish Armed Forces Health Services

Introduction: Early in January 2001, the media reported an increased frequency of leukemia among Italian soldiers who had served in the Balkans. It was claimed that the increased frequency was caused by exposure to depleted uranium (DU) coming from shells used in the areas. On 05 January, the Danish Armed Forces Health Services (DAFHS) established a 24-hour, physician-manned, telephone line. During the first three days, 120 people contacted the line. Two former deployed soldiers reported leukemia after having returned from the Balkans. On 09 January, the Danish Ministry of Defense decided to offer a free health examination and blood testing to all soldiers who had served in the Balkans or the Gulf since 1991.

Material and Methods: The offer was given to 14,868 formerly deployed soldiers. Other ministries decided on 10 January to provide a similar offer to their employees who had served in the same areas. The size of the civilian population is unknown. It was decided that the health examination should be carried out by general practitioners (GPs), and that the results and bill should be sent to the DAFHS. Thus, the material consisted of all of the reports sent from the GPs to the DAFHS.

Results: By 31 December 2001, 4,228 reports were received. Of these, 3,716 people (87.9\%) were military and 512 came from other authorities. No further cases of leukemia were found. The number of reports received during the end of 2001 was very low, and the Danish government decided to close the arrangement by 01 April 2002.

Conclusion: Nearly one-third of the Danish soldiers who had been deployed passed the free health examination. At least from a psychological point of view, the heath examination seemed appropriate.

Keywords: Balkans; Gulf War; leukemia; media; uranium Prebosp Disast Med 2002;17:s8.

\section{International Disaster Relief - How Can We Improve? \\ Fjar $R B$ \\ HQ Defence Command, Medical Division, Oslo, Norway}

Introduction: International humanitarian aid has a strong position in Norwegian tradition. During the last decades, frequent humanitarian emergencies have occurred, with an increasing number of humanitarian organisations taking part in providing assistance. However, need assessments, medical intelligence, and co-ordination of the aid often are sparse, often resulting in the provision of ineffective and expensive assistance.

Methods: The eight ELEMENTS of Primary Health Care as advocated by WHO, are given indicators to estimate the level of healthcare services in a country, and can be used in the evaluation of the impact of the disaster. Healthcare is related to the climatic, geographic, political, and religious situation in the affected country. The method was tested after the earthquake in Gujarat, India in January 2001, and the volcano eruption in Goma, Zaire in January 2002.

Results: Evaluation of the situation in the countries as a whole revealed a complex situation and severe deficiencies in the health system that added to the severity of the acute disaster. Disaster relief to the disaster victims was delayed for various reasons: 1) Efficient co-ordination was lacking; 2) Insufficient and partly irrelevant relief were provided; or 3 ) the needs for relief were overestimated.

Conclusion: To optimise the effectiveness of limited resources, disaster preparedness, and the provision of feasible and necessary aid is of utmost importance. An assessed, rapid crises intervention may be achieved by continual watching of the world's situation by a Main Rescue Central. A panel of experts could evaluate and co-ordinate the disaster response and make use of stored emergency material and emergency teams. A successful disaster response will depend on profound medical intelligence and socio-geographic mapping in advance, during, and after the event(s) that causde the disaster. More effective and feasible use of the equipment co-ordinated with the activities provided by the rest of the world, is necessary.

Keywords: aid, humanitarian; coordination; earthquake; intelligence; mapping; need assessment; preparedness; Norway; volcano, eruption of

Prebosp Disast Med 2002;17:s8.

\section{Suicide after Service in UN Peacekeeping Missions - A Danish Pilot Study \\ Hansen-Scbwartz $J,{ }^{1}$ Jessen $G,{ }^{2}$ Andersen $K,{ }^{3}$ Jorgensen $\mathrm{HO}^{1}$}

1. Defence Medical Training Centre, Denmark

2. The VHR Group, Odense, Denmark

3. Centre for Suicidological Research, Odense, Denmark

Introduction: Humiliation, direct combat, exposure to snipers, or seeing comrades wounded or killed may trigger immediate responses such as anger, fear, or guilt. However, reactions also may arise later as the post-traumatic stress disorder (PTSD), a condition associated with an increased risk of suicide. 1

Method: Personnel assigned to international missions from 1995 to 1997 were compared to the Danish Register of Suicide. Suicide within one year of observation was considered relevant.

Results: A total of 3,859 Danish United Nation's soldiers were included. One soldier died in a car accident two months after discharge, two soldiers committed suicide less than one month before deployment, and two soldiers committed suicide within one year of discharge. Both of these latter soldiers belonged to the same unit, a unit that suffered heavy artillery strike with a number of casualties and heavy material damage.

Discussion: In a matched background population, approximately 3 suicides were to be expected. Thus, there do not 